\title{
Variations in male-female infant ratios among births to Canadian- and Indian-born mothers, 1990-2011: a population-based register study
}

\author{
Marcelo L. Urquia PhD, Joel G. Ray MD MSc, Susitha Wanigaratne PhD, Rahim Moineddin PhD, \\ Patricia J. O'Campo PhD
}

See also www.cmaj.ca/lookup/doi/10.1503/cmaj.160183 and www.cmaj.ca/lookup/doi/10.1503/cmaj.151074

\section{Abstract}

Background: We assessed variations in the male-female infant ratios among births to Canadian-born and Indian-born mothers according to year of birth, province and country of birth of each parent.

Methods: In this population-based register study, we analyzed birth certificates of 5853970 singleton live births to Canadian-born and 177990 singleton live births to Indian-born mothers giving birth in Canada from 1990 to 2011. Male-female ratios were stratified by live birth order and plotted by year of birth. Logistic regression was used to assess whether ratios varied between Canadian provinces and according to the birthplace of each parent. The deficit in the number of girls was estimated using bootstrap methods.

Results: Among Canadian-born mothers, male-female ratios were about 1.05, with negligible fluctuations by birth order, year and province. Among Indian-born mothers, the overall male-female ratio at the third birth was 1.38 (95\% confidence interval [Cl] $1.34-1.41)$ and was $1.66(95 \% \mathrm{Cl} 1.56-1.76)$ at the fourth or higher-order births. There was little variability in the ratios between provinces. Couples involving at least 1 Indian-born parent had higher than expected male-female ratios at the second and higher-order births, particularly when the father was Indian-born. The deficit in the expected number of girls among Indian immigrants to Canada in the study period was estimated to be 4472 (95\% Cl 3211-5921).

Interpretation: Fewer than expected girls at the third and higher-order births have been born to Indian immigrants across Canada since 1990. This trend was also seen among couples of mixed nativity, including those involving a Canadian-born mother and an Indian-born father. Fathers should be considered when investigating sex ratios at birth.

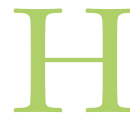
igher-than-expected male to female (M:F) ratios at birth have been seen in several countries, particularly in Asia. ${ }^{1-8}$ High M:F ratios at birth have also been seen among some Asian immigrant groups to industrialized countries, ${ }^{9-14}$ including Canada. ${ }^{11,13}$ In most populations, the normal ratio ranges from 1.03 to $1.07,5,15-17$ although the reasons why male newborns slightly outnumber girls remain unknown. ${ }^{18}$ Higher-than-expected M:F ratios have been seen in Ontario among second births of South Korean immigrants and second and higher-order births of Indian immigrants. The M:F ratio among third-order live births to Indian-born mothers who migrated to Ontario was $1.36 .{ }^{13}$ Census data from Canada noted an M:F ratio of 1.90 among third-order births to Indian-born women with 2 previous girls. ${ }^{11}$

The extent to which skewed M:F ratios have existed among Indian immigrants to Canada is unknown in terms of time trends or by province. Although previous research focused on the country of birth of the mother, no consideration has been given to the influence of the father's country of birth on M:F ratios, particularly among mixed nativity couples, who are increasingly more common within multicultural societies like Canada. ${ }^{19}$

Herein, we focused on immigrants from India because they have the highest documented M:F ratios globally, and

Competing interests: None declared.

This article has been peer reviewed.

Correspondence to: Marcelo Urquia, urquiam@smh.ca

CMAJ Open 2016. DOI:10.9778/cmajo.20150141 
they are a top contributor of births to immigrants in Canada. The large number of births to Indian immigrants in Canada allows the assessment of temporal trends and provincial variations in the M:F ratios among live births to women born in Canada or India. We also assessed whether the M:F ratios differed if the mother and father were from the same or different countries, and further estimated the deficit in the expected number of girls among births to immigrants from India.

\section{Methods}

\section{Setting}

The eligible study population was defined as all singleton live births to Canadian- and Indian-born mothers giving birth in Canada from Jan. 1, 1990, to Dec. 31, 2011.

\section{Design}

This is a population-based register study using national birth certificate data. We restricted our main analyses to singleton live births among mothers born in Canada or India, who had complete and plausible information about maternal country of birth, number of previous live births, infant sex, province and year of birth. We excluded births outside of Canada, irrespective of whether the mother was Canadian-born, and births in the Yukon, Northwest Territories and Nunavut, because of the negligible number of births to Indian-born women in these jurisdictions.

\section{Sources of data}

We used national birth cohorts from 1990 to 2011, as contained in the Canadian Vital Statistics Birth Database administered by Statistics Canada. The database consists of birth certificate data provided by provincial and territorial vital statistics registrars. Although the current database begins in 1974, maternal country of birth was poorly captured before 1990 , because immigrants from India were collapsed into a single "Asia" group.

\section{Statistical analysis}

A male to female ratio is an odds ratio $\left(P_{\text {male }} /\left(1-P_{\text {male }}\right)\right.$. We used intercept-only logistic regression models to calculate M:F ratios (i.e., the odds of a male) within each stratum of birth order (i.e., first, second, third or fourth birth and higher). Birth order was assessed by a field in the Canadian Vital Statistics Birth Database reporting the total number of previous live births each mother had at each index birth, irrespective of whether they occurred in Canada. To assess linear trends in the M:F ratio over time, we used the CochranArmitage test for binomial proportions. Logistic regression was then used to obtain adjusted odds ratios (ORs) with $95 \%$ confidence intervals (CIs) to compare the M:F ratios within strata of birth order between provinces. Ontario served as the referent, because it is the largest Canadian province with the largest concentration of Indian immigrants. ${ }^{13}$

The deficit in the expected number of girls was calculated by $M /(F+x)=1.07$, where $x$ is the number of "missing girls."
To indicate the presence of a deficit in the number of girls, we only considered M:F ratios above 1.07 - the upper limit of the established normal biological variability. ${ }^{5,15-17}$ The $95 \%$ CIs were calculated using bootstrap with 10000 replications. The lower bound was set to be 0 when negative.

Reporting guidelines for the Canadian Vital Statistics Birth Database mandate the masking of frequencies to prevent reidentification of individuals. We therefore used controlled rounding techniques to randomly approximate all counts to the nearest multiple of 5 . Use of the data for this study was approved by Statistics Canada and by the Research Ethics Board of St. Michael's Hospital, Toronto.

\section{Results}

There were 6074115 singleton live births in Canada to Canadian- or Indian born mothers in the 22-year period spanning 1990-2011. Of these, we excluded 42155 records $(0.69 \%)$ for 1 or more of the following reasons: missing information on the number of previous live births (3910 [0.06\%]), infant's sex unknown (295 [<0.01\%]), missing or out of range maternal age $(7440[0.12 \%])$, infant's province of birth unknown (185 [0.01\%]), and birth occurred in Yukon, Northwest Territories or Nunavut (33 105 [0.55\%]). The final sample included 6031960 live births, of which 5853970 were to Canadian-born mothers and 177990 were to Indian-born mothers.

About $45 \%$ of all births to Canadian-born mothers occurred in $\mathrm{BC}$ and Ontario, in contrast to $85 \%$ of births to Indian-born mothers (Table 1). There were relatively few births to Indian-born mothers in Quebec. Most fathers were born in the same country as the mother. Canadian-born mothers tended to have more births than Indian-born mothers after 2 previous children. Unlike Canadian-born mothers, among Indian-born women, the proportion of male infants noticeably increased according to birth order and maternal age group. Unlike Canadian-born mothers, most of the Indian-born mothers were married (Table 1).

Crude $\mathrm{M}: \mathrm{F}$ ratios among Canadian-born mothers showed little, if any, fluctuation according to birth order and year of birth, ranging between 1.03 and 1.06 (Figure 1). In contrast, crude $\mathrm{M}: \mathrm{F}$ ratios among Indian-born women were consistently high for third and fourth or higher-order births (Figure 1). Among Indian-born mothers, the overall M:F ratio at the third birth was 1.38 (95\% CI 1.34-1.41) and increased over time $(p<0.05)$ from 1.15 (95\% CI 1.04-1.27) in 19901991 to 1.38 (95\% CI 1.27-1.50) in 2010-2011, after having peaked at 1.57 (95\% CI 1.43-1.72) in 2000-2001. Conversely, the overall $\mathrm{M}: \mathrm{F}$ ratio at the fourth and higher-order births among Indian-born mothers was 1.66 (95\% CI 1.56-1.76), declining from 1.84 (95\% CI 1.51-2.24) in 1990-1991 to 1.45 (95\% CI 1.22-1.73) in 2010-2011 (Figure 1). A post hoc analysis suggested that these contrasting trends between thirdorder and fourth or higher-order births among Indian-born mothers were accompanied by parallel trends toward smaller families. Specifically, the proportion of third-order births among all births to Indian-born women decreased from 


\section{OPEN}

Research

$16.4 \%$ in $1990-1991$ to $11.3 \%$ in $2010-2011(p<0.01)$, whereas the proportion of fourth and higher-order births decreased from $4.4 \%$ in $1990-1991$ to $2.5 \%$ in $2010-2011$ $(p<0.01)$.

Among Canadian-born mothers, M:F ratios remained unchanged within strata of birth order comparing other provinces to Ontario (Table 2). For Indian-born mothers, provincial variation was also minimal, except among fourth and higher-order births in British Columbia (adjusted OR 1.28, 95\% CI 1.12-1.47) (Table 2).

For the assessment of $\mathrm{M}: \mathrm{F}$ ratios within groups jointly defined by maternal and paternal country of birth, we further included 1464330 infants born to mothers not born in Canada or India, after exclusions, obtaining 7496290 births for these analyses.

Comparing M:F ratios by maternal and paternal country of birth, the highest ratio was among 2 Indian-born parents (Table 3). Since most births to Indian-born parents were to couples in which both parents were from India, this arrangement explained about $95 \%$ of the deficit in the number of girls. Interestingly, the presence of an Indian-born father was associated with higher than expected $\mathrm{M}: \mathrm{F}$ ratios at the second and higher birth orders, irrespective of whether the mother was born in India.

\begin{tabular}{|c|c|c|c|c|}
\hline \multirow[b]{2}{*}{ Characteristics } & \multicolumn{2}{|c|}{ Canadian-born mothers } & \multicolumn{2}{|c|}{ Indian-born mothers } \\
\hline & Live births (\%) & Male, \% & Live births (\%) & Male, \% \\
\hline No. of births & $5853970(100.0)$ & 51.3 & $177990(100.0)$ & 52.8 \\
\hline \multicolumn{5}{|l|}{ Period of birth } \\
\hline 1990-1999 & 2856050 (48.8) & 51.3 & 64775 (36.4) & 53.1 \\
\hline 2000-2009 & 2476435 (42.3) & 51.3 & $92155(51.8)$ & 52.8 \\
\hline 2010-2011 & $521485(8.9)$ & 51.3 & $21060(11.8)$ & 51.9 \\
\hline \multicolumn{5}{|l|}{ Province of birth } \\
\hline British Columbia & $635670(10.8)$ & 51.2 & 55740 (31.3) & 52.9 \\
\hline Alberta & 720805 (12.3) & 51.3 & $17770(10.0)$ & 52.4 \\
\hline Manitoba-Saskatchewan & $558425(9.5)$ & 51.2 & $4005(2.2)$ & 54.3 \\
\hline Ontario & 1987715 (34.0) & 51.3 & 94855 (53.3) & 52.8 \\
\hline Quebec & $1455615(24.9)$ & 51.4 & $4945(2.8)$ & 51.5 \\
\hline Atlantic Canada* & $495740(8.5)$ & 51.2 & $675(0.4)$ & 51.1 \\
\hline \multicolumn{5}{|l|}{ Father's birthplace } \\
\hline Canada & $4967520(84.8)$ & 51.3 & $7195(4.1)$ & 51.7 \\
\hline India & $9315(0.2)$ & 52.1 & $155760(87.5)$ & 52.9 \\
\hline Other/unknown & $877140(15.0)$ & 51.1 & $15030(8.4)$ & 52.0 \\
\hline \multicolumn{5}{|l|}{ Birth order } \\
\hline 1st & $2635520(45.0)$ & 51.3 & 82355 (46.3) & 51.5 \\
\hline 2nd & $2056130(35.1)$ & 51.3 & 69695 (39.2) & 52.1 \\
\hline $3 r d$ & $783970(13.4)$ & 51.2 & $21090(11.8)$ & 57.9 \\
\hline 4th or higher & $378350(6.5)$ & 51.1 & $4850(2.7)$ & 62.4 \\
\hline \multicolumn{5}{|l|}{ Mother's age at birth, yr } \\
\hline $15-19$ & $357805(6.1)$ & 51.4 & $1005(0.6)$ & 50.7 \\
\hline $20-24$ & 1121195 (19.2) & 51.3 & $32785(18.4)$ & 52.0 \\
\hline $25-29$ & 1938765 (33.1) & 51.3 & $72820(40.9)$ & 52.2 \\
\hline $30-34$ & $1697830(29.0)$ & 51.3 & $52035(29.2)$ & 53.4 \\
\hline $35-55$ & 738380 (12.6) & 51.2 & 19345 (10.9) & 54.8 \\
\hline \multicolumn{5}{|l|}{ Father's age at birth, yr } \\
\hline $15-24$ & 705155 (12.1) & 51.4 & $8310(4.7)$ & 52.1 \\
\hline $25-34$ & 3391905 (57.9) & 51.3 & $113710(63.9)$ & 52.3 \\
\hline $35-44$ & $1275765(21.8)$ & 51.2 & $48805(27.4)$ & 53.8 \\
\hline $45-54$ & $97345(1.7)$ & 51.4 & $3460(1.9)$ & 54.3 \\
\hline $55-80$ & $7070(0.1)$ & 51.6 & $235(0.1)$ & 51.1 \\
\hline Unknown & $376735(6.4)$ & 50.8 & $3465(2.0)$ & 53.4 \\
\hline \multicolumn{5}{|l|}{ Mother's marital status } \\
\hline Single, never married & $1828175(31.2)$ & 51.3 & $1520(0.9)$ & 53.0 \\
\hline Married & $3448310(58.9)$ & 51.3 & $167920(94.3)$ & 52.8 \\
\hline Widowed, divorced or separated & $104585(1.8)$ & 51.3 & $810(0.5)$ & 51.9 \\
\hline Unknown & 472905 (8.1) & 51.0 & $7740(4.3)$ & 51.9 \\
\hline
\end{tabular}


A

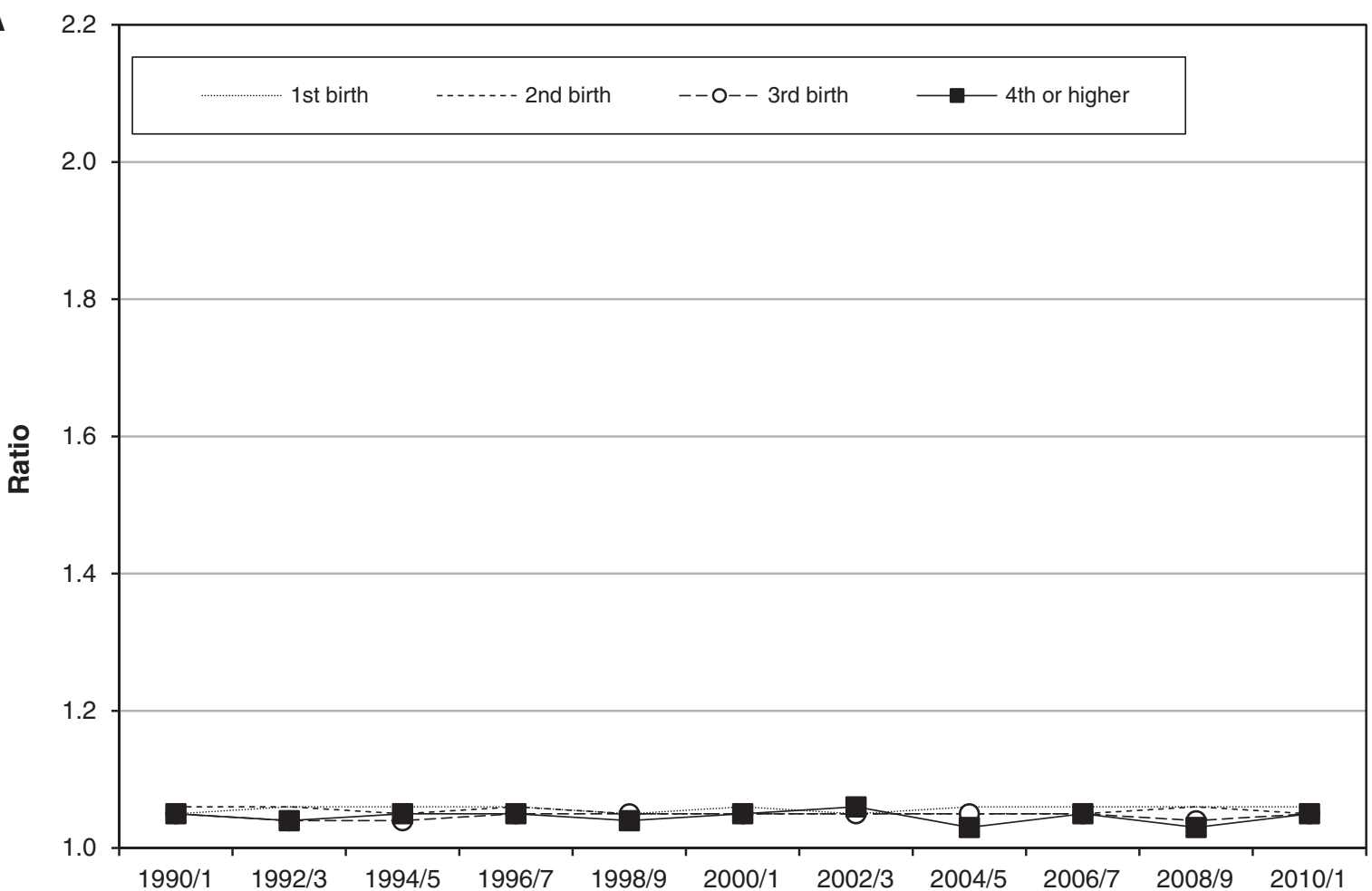

B

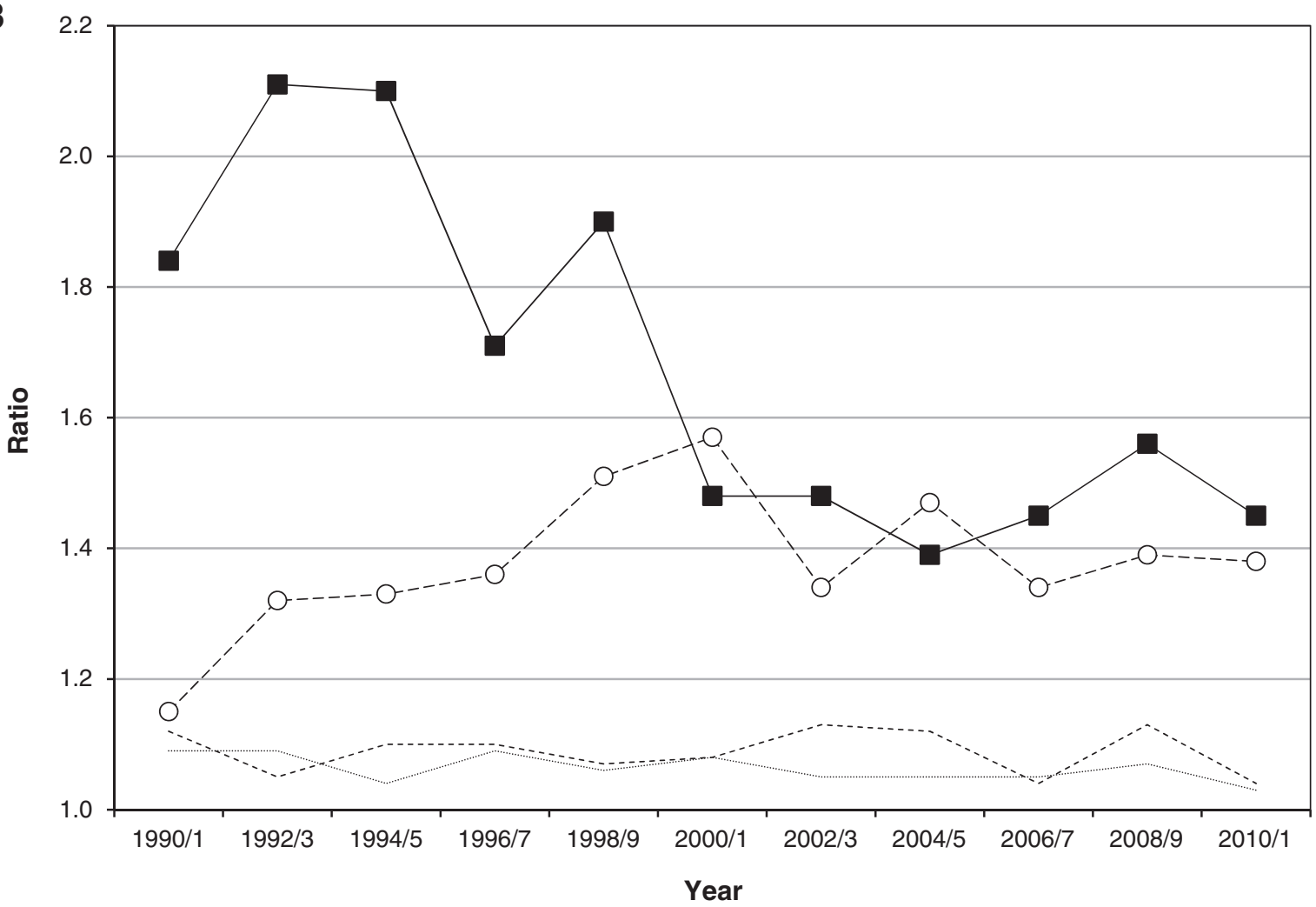

Figure 1: Time trends in male-female ratios among live births to Canadian- (A) and Indian-born (B) mothers, according to live birth order, 1990-2011. 
For mixed nativity unions, the $\mathrm{M}: \mathrm{F}$ ratios were higher at the third or fourth and higher-order births if 1 of the parents was Indian-born, but the most marked effect at the fourth birth was among couples involving a Canadian-born mother and an Indian-born father (M:F ratio $1.46 ; 95 \%$ CI 1.18 1.82), followed by couples involving an Indian-born mother and a father not born in either Canada or India (M:F ratio 1.38 ; 95\% CI 1.16-1.64) (Table 3).

The top birthplaces of mothers not born in Canada or India coupled with an Indian-born father were the United Kingdom (32\%), followed by Pakistan (10\%) and the Philippines (5\%). The top birthplaces of fathers not born in Canada or India coupled with an Indian-born mother were unknown (48\%), followed by the UK (32\%), Pakistan (6\%) and Sri Lanka (4\%).

\section{Interpretation}

\section{Main findings}

We evaluated most registered live births to Indian immigrants to Canada for more than 2 decades, and compared these births to nearly all live births to Canadian-born parents.
Among Indian immigrants, high M:F ratios were observed at third-order and fourth or higher-order births, which did not vary considerably across provinces. We conservatively estimated that 4472 daughters of Indian immigrants to Canada were unaccounted for over the last 2 decades - so-called "missing girls"7-9 — largely among couples of 2 Indian-born parents (89.4\%), but also among couples including 1 Canadianborn parent.

Our findings highlight the magnitude of the skewed sex ratios at birth among Indian immigrants to Canada but do not explain them. There are numerous speculations regarding the factors that may affect natural sex ratios, most of which are surrounded by conflicting evidence. ${ }^{18}$ Human intervention, in the form of prenatal sex selection, specifically induced abortion of female fetuses after prenatal ultrasonography, is the most commonly cited explanation in settings where son preference and strong patriarchal cultures are prevalent, although direct evidence of such a link remains scarce. ${ }^{2,20}$ Our companion paper adds plausibility to such a claim by showing that high M:F ratios are associated with preceding induced abortions in Ontario. ${ }^{21}$ Because son-biased sex ratios among Indian immigrants did not differ according

Table 2: Male-female (M:F) sex ratios at birth among Canadian- and India-born mothers, by live birth order, and adjusted odds ratios for giving birth to a male infant in different Canadian provinces, by maternal birthplace and birth order, Canada, 1990-2011

\begin{tabular}{|c|c|c|c|c|c|c|c|c|}
\hline \multirow{2}{*}{$\begin{array}{l}\text { Mother's } \\
\text { birthplace }\end{array}$} & \multicolumn{8}{|c|}{ Live birth order } \\
\hline & \multicolumn{2}{|c|}{ 1st birth } & \multicolumn{2}{|c|}{ 2nd birth } & \multicolumn{2}{|c|}{ 3rd birth } & \multicolumn{2}{|c|}{ 4th birth or higher } \\
\hline \multicolumn{9}{|l|}{ Canada } \\
\hline By province* & Males/females & $\begin{array}{l}\text { Adjusted OR† } \\
\quad(95 \% \mathrm{Cl})\end{array}$ & Males/females & $\begin{array}{l}\text { Adjusted OR† } \\
(95 \% \mathrm{Cl})\end{array}$ & Males/females & $\begin{array}{l}\text { Adjusted OR† } \\
\quad(95 \% \mathrm{Cl})\end{array}$ & Males/females & $\begin{array}{l}\text { Adjusted OR† } \\
(95 \% \mathrm{Cl})\end{array}$ \\
\hline British Columbia & 150 645/142 595 & $1.00(1.00-1.01)$ & $113790 / 108470$ & $1.00(0.99-1.01)$ & $41985 / 40370$ & $0.99(0.97-1.00)$ & 19 250/18 565 & $0.98(0.96-1.00)$ \\
\hline Alberta & $157590 / 149540$ & $1.00(0.99-1.01)$ & 126 080/118940 & $1.01(1.00-1.02)$ & 53 990/51670 & $0.99(0.98-1.00)$ & 31 995/31000 & $0.98(0.96-1.00)$ \\
\hline $\begin{array}{l}\text { Manitoba- } \\
\text { Saskatchewan }\end{array}$ & $113295 / 107115$ & $1.00(0.99-1.01)$ & 90 070/86 445 & $0.99(0.98-1.00)$ & 46 000/44 160 & $0.99(0.97-1.00)$ & 36 405/34 935 & $0.99(0.97-1.01)$ \\
\hline $\begin{array}{l}\text { Ontario } \\
\text { (reference) }\end{array}$ & $461840 / 438865$ & 1.00 & 364 210/346 025 & 1.00 & $135840 / 128685$ & 1.00 & 57 680/54 570 & 1.00 \\
\hline Quebec & 351 060/331 635 & $1.00(1.00-1.01)$ & 269 580/255 200 & $1.01(1.00-1.01)$ & 91 755/87 180 & $1.00(0.99-1.01)$ & 35 325/33 885 & $0.98(0.96-1.00)$ \\
\hline Atlantic Canada & $118815 / 112525$ & $1.00(0.99-1.01)$ & 90 590/86 730 & $0.99(0.98-1.00)$ & $31715 / 30620$ & $0.98(0.97-1.00)$ & 12 765/11980 & $1.01(0.99-1.03)$ \\
\hline $\begin{array}{l}\text { M:F ratio in all } \\
\text { provinces }\end{array}$ & $1.06(1.05-1.06)$ & & $1.05(1.05-1.06)$ & & $1.05(1.04-1.05)$ & & $1.05(1.04-1.05)$ & \\
\hline \multicolumn{9}{|l|}{ India } \\
\hline British Columbia & 13 215/12 370 & $1.00(0.97-1.03)$ & $10925 / 10260$ & $0.97(0.94-1.00)$ & 4 345/3 095 & $1.02(0.96-1.08)$ & $1020 / 510$ & $1.28(1.12-1.47)$ \\
\hline Alberta & $4255 / 4075$ & $0.99(0.94-1.03)$ & 3 730/3 385 & $1.00(0.95-1.05)$ & $1110 / 855$ & $0.94(0.85-1.03)$ & $220 / 135$ & $1.05(0.84-1.32)$ \\
\hline $\begin{array}{l}\text { Manitoba- } \\
\text { Saskatchewan }\end{array}$ & $1030 / 910$ & $1.07(0.98-1.17)$ & $800 / 700$ & $1.04(0.94-1.16)$ & $280 / 190$ & $1.06(0.88-1.28)$ & $65 / 35$ & $1.33(0.87-2.04)$ \\
\hline $\begin{array}{l}\text { Ontario } \\
\text { (reference) }\end{array}$ & 22 505/21 275 & 1.00 & 19 795/17980 & 1.00 & 6 150/4 445 & 1.00 & $1620 / 1085$ & 1.00 \\
\hline Quebec & $1225 / 1160$ & $1.00(0.92-1.08)$ & $930 / 925$ & $0.91(0.83-1.00)$ & $300 / 255$ & $0.86(0.72-1.02)$ & $90 / 55$ & $0.91(0.65-1.28)$ \\
\hline Atlantic Canada & $170 / 165$ & $1.01(0.82-1.26)$ & $130 / 130$ & $0.93(0.73-1.18)$ & $65 \ddagger$ & $\ddagger$ & $15 \ddagger$ & $\ddagger$ \\
\hline $\begin{array}{l}\text { M:F ratio in all } \\
\text { provinces }\end{array}$ & $1.06(1.05-1.08)$ & & $1.09(1.07-1.10)$ & & $1.38(1.34-1.41)$ & & $1.66(1.56-1.76)$ & \\
\hline $\begin{array}{l}\text { Note: } \mathrm{Cl}=\text { confider } \\
\text { ^Except Yukon, No } \\
\text { †Adjusted for perio } \\
\ddagger \text { M:F ratios based }\end{array}$ & $\begin{array}{l}\text { ntervals, OR = od } \\
\text { est Territories and } \\
\text { birth, maternal a } \\
\text { ewer than } 100 \text { obs }\end{array}$ & $\begin{array}{l}\text { dds ratio. } \\
\text { d Nunavut. } \\
\text { ge groups, patern } \\
\text { servations are no }\end{array}$ & disclosed, therefo & these frequencies & 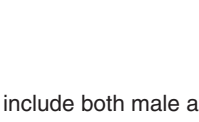 & and female infants. & & \\
\hline
\end{tabular}


to Canadian province in this study, those Ontario findings are likely to apply to the rest of Canada. A qualitative study supports the link between son preference and prenatal sex selection among Indian immigrants in the United States, ${ }^{22}$ not limited to induced abortion but also involving assisted reproductive technologies. Future studies may further elucidate the specific contribution of the distinct pathways leading to sex-biased ratios at birth.

\begin{tabular}{|c|c|c|c|c|c|c|}
\hline $\begin{array}{l}\text { Mother's } \\
\text { birthplace }\end{array}$ & $\begin{array}{l}\text { Father's } \\
\text { birthplace }\end{array}$ & $\begin{array}{l}\text { Birth } \\
\text { order }\end{array}$ & Males/females & $\mathrm{M}: \mathrm{F}$ ratio $(95 \% \mathrm{Cl})$ & $\begin{array}{l}\text { Estimated deficit in the } \\
\text { no. of girls }(95 \% \mathrm{Cl})\end{array}$ & $\begin{array}{c}\text { Estimated } \\
\text { percentage } \\
\text { deficit in girls }\end{array}$ \\
\hline \multirow[t]{4}{*}{ Canada } & Canada & 1 & 1127 735/1066 260 & $1.06(1.05-1.06)$ & * & \\
\hline & & 2 & 917 940/871 550 & $1.05(1.05-1.06)$ & * & \\
\hline & & 3 & 344 585/328 605 & $1.05(1.04-1.05)$ & * & \\
\hline & & $\geq 4$ & 159 060/151 785 & $1.05(1.04-1.06)$ & * & \\
\hline \multirow[t]{4}{*}{ Canada } & India & 1 & $2345 / 2275$ & $1.03(0.97-1.09)$ & * & \\
\hline & & 2 & $1695 / 1540$ & $1.10(1.03-1.18)$ & $44(0-152)$ & 0.98 \\
\hline & & 3 & $605 / 510$ & $1.19(1.05-1.33)$ & $55(0-119)$ & 1.23 \\
\hline & & $\geq 4$ & $205 / 140$ & $1.46(1.18-1.82)$ & $52(17-86)$ & 1.16 \\
\hline \multirow[t]{4}{*}{ Canada } & Other & 1 & $223175 / 213735$ & $1.04(1.04-1.05)$ & * & \\
\hline & & 2 & 134 680/128 720 & $1.05(1.04-1.05)$ & * & \\
\hline & & 3 & 56 095/53 570 & $1.05(1.03-1.06)$ & * & \\
\hline & & $\geq 4$ & 34 150/33010 & $1.03(1.02-1.05)$ & * & \\
\hline \multirow[t]{4}{*}{ India } & Canada & 1 & $1970 / 1855$ & $1.06(1.00-1.13)$ & * & \\
\hline & & 2 & $1305 / 1235$ & $1.06(0.98-1.14)$ & * & \\
\hline & & 3 & $370 / 310$ & $1.19(1.03-1.39)$ & $36(0-86)$ & 0.81 \\
\hline & & $\geq 4$ & $80 / 75$ & $1.07(0.78-1.46)$ & * & \\
\hline \multirow[t]{4}{*}{ India } & India & 1 & 36 640/34 550 & $1.06(1.05-1.08)$ & * & \\
\hline & & 2 & 32 255/29 490 & $1.09(1.08-1.11)$ & 657 (181-1 129) & 14.69 \\
\hline & & 3 & $10885 / 7775$ & $1.40(1.36-1.44)$ & 2398 (2141-2 655) & 53.62 \\
\hline & & $\geq 4$ & $2640 / 1525$ & $1.73(1.63-1.84)$ & $942(824-1060)$ & 21.06 \\
\hline \multirow[t]{4}{*}{ India } & Other & 1 & $3785 / 3555$ & $1.06(1.02-1.11)$ & * & \\
\hline & & 2 & $2755 / 2650$ & $1.04(0.99-1.10)$ & * & \\
\hline & & 3 & $960 / 790$ & $1.22(1.11-1.34)$ & $107(28-187)$ & 2.39 \\
\hline & & $\geq 4$ & $310 / 225$ & $1.38(1.16-1.64)$ & 65 (20-109) & 1.45 \\
\hline \multirow[t]{4}{*}{ Other } & Canada & 1 & 81 970/77 410 & $1.06(1.05-1.07)$ & * & \\
\hline & & 2 & 63 990/60 275 & $1.06(1.05-1.07)$ & * & \\
\hline & & 3 & 23 165/22 275 & $1.04(1.02-1.06)$ & * & \\
\hline & & $\geq 4$ & $11365 / 10595$ & $1.07(1.04-1.10)$ & * & \\
\hline \multirow[t]{4}{*}{ Other } & India & 1 & 2 045/1970 & $1.04(0.98-1.10)$ & * & \\
\hline & & 2 & $1795 / 1615$ & $1.11(1.04-1.19)$ & $63(0-175)$ & 1.41 \\
\hline & & 3 & $695 / 630$ & $1.10(0.99-1.23)$ & $20(0-89)$ & 0.45 \\
\hline & & $\geq 4$ & $255 / 205$ & $1.24(1.03-1.49)$ & $33(0-74)$ & 0.74 \\
\hline \multirow[t]{4}{*}{ Other } & Other & 1 & 233 015/220 120 & $1.06(1.05-1.06)$ & * & \\
\hline & & 2 & 200 585/190 785 & $1.05(1.04-1.06)$ & * & \\
\hline & & 3 & 84 170/80 160 & $1.05(1.04-1.06)$ & * & \\
\hline & & $\geq 4$ & $48965 / 46275$ & $1.06(1.04-1.07)$ & * & \\
\hline Total & & & 3848 240/3 648050 & $1.06(1.05-1.06)$ & 4472 (3 211-5 921) & 100.00 \\
\hline
\end{tabular}


It appears that skewed M:F ratios among some Indian immigrants to Canada have been present for at least 2 decades, accruing about 4472 "missing girls." This estimate may be conservative, because calculations of the deficit in the number of girls based on M:F ratios do not account for repeated induced abortions of female fetuses. ${ }^{21}$ Since the biological probability of having a male live birth is independent of the sex of the previous births of the same mother, ${ }^{23}$ consecutive pregnancies of female fetuses are likely to occur. Some couples may, therefore, undergo repeated induced abortions until they carry a male fetus. ${ }^{21,22}$ Our study confirms that most of the deficit of girls occurs at the third birth $(n=2616,58.5 \%)$. However, the deficit of girls is higher among fourth and higherorder births $(n=1092,24.4 \%)$ than among second-order births $(n=764,17.1 \%)$, despite the larger number of secondorder births. Few previous studies were large enough to examine $\mathrm{M}: \mathrm{F}$ ratios at fourth and higher-order births. ${ }^{6,13}$ Unlike in our previous study that was limited to Ontario, and in which we included live and stillbirths in defining birth order ${ }^{13}$ here we only included live births. Counting stillbirths dilutes the association between birth order and M:F ratios, since fertility decisions are thought to be made based on the current number and sex of the living children in the family. ${ }^{1}$

We found increasing temporal trends in the M:F ratio at the third birth paralleled by decreasing trends at higher-order births. This is likely a function of declining trends in family size over time. Under the hypothesis of the son preference, securing a boy by the third birth may release the pressure of getting a boy in subsequent births, although some couples may still recourse to induced abortions to control family size after having had a son. ${ }^{2}$ The lack of substantial provincial differences in the sex ratios of births to Indian immigrants suggests that the place of origin may be more influential than that of destination. Although the M:F ratio at the fourth birth was somewhat higher in British Columbia, Manitoba and Saskatchewan than in Ontario - something worthy of further exploration - it was higher than expected in all Canadian provinces, suggesting that our findings may be generalized to similar Indian diasporas. Finally, our study quantified the contribution of both maternal and paternal country of birth to M:F newborn sex ratios. Paternal influence has been postulated to be a key influence on $\mathrm{M}: \mathrm{F}$ ratios,${ }^{24}$ and our findings suggest that this is so even among couples of mixed nativity. Certainly, some Canadian-born mothers may have been of second-generation Indian ancestry. Data from the 2001 and 2006 Canadian censuses reported a M:F ratio of 1.32 within households of "Asian" couples with 2 previous girls, in which one or both parents were Canadian-born. ${ }^{11}$ Interestingly, among mixed nativity couples, most parents in the "Other" group (i.e., not born in Canada or India) were born in the UK, where a large Indian diaspora exists, including secondgeneration Indians. Further studies may clarify to what extent the skewed sex ratios among mixed nativity couples involve second-generation Indians. Although mixed nativity couples accounted for only $10.6 \%$ of the total deficit of girls in the current study, it remains to be seen how M:F ratios will change within this emerging demographic group. ${ }^{19}$

\section{Limitations}

The Canadian Vital Statistics Birth Database does not distinguish between births from the same mother and, therefore, we could not examine finer patterns in the M:F ratios according to the sex of the previous siblings. Although our aggregation at the level of live birth order would have diluted the effect sizes observed herein, this limitation should not have severely underestimated the number of "missing girls," owing to our large sample size. Second, the database does not have data on induced abortions, which would provide more direct information about the practice of prenatal sex selection. However, our companion paper addresses this limitation. ${ }^{21}$ Third, although we used novel data about both maternal and paternal country of birth, recording of father's birthplace was not as complete as that of the mother. Finally, the database does not include data on the year of immigration. Such information could help to determine whether duration of residence in Canada leads to more balanced M:F ratios, as seen among newborns of 2 Canadian-born parents. Finally, grandparents' birthplace was not captured, so second-generation immigrants could not be identified.

Despite these limitations, this study provides a comprehensive portrait of skewed $\mathrm{M}: \mathrm{F}$ ratios among Indian immigrants to Canada, including M:F ratios among fourth and higherorder births, something not possible in studies using Canadian census data. ${ }^{11}$ Our inclusion of fourth and higher-order births specifically revealed that "missing girls" are common in this stratum, and that the failure to account for fourth and higher-order births may underestimate the calculation of the deficit in the number of girls by about $25 \%$.

\section{Conclusion}

This study provides a comprehensive account of "missing girls" to Indian immigrants in Canada. A higher than expected $\mathrm{M}: \mathrm{F}$ ratio at birth among Indian immigrants may have produced a deficit of about 4472 girls over the past 2 decades, with little variation across Canadian provinces. Furthermore, our study highlights the importance of the father as a key figure to consider when conducting further research on the topic or designing strategies to curve down the skewed sex ratios within certain communities.

\section{References}

1. Arnold F. Measuring the effect of sex preference on fertility: the case of Korea. Demography 1985;22:280-8.

2. Arnold F, Kishor S, Roy TK. Sex-selective abortions in India. Popul Dev Rev 2002;28:759-85.

3. Chatterjee P. Sex ratio imbalance worsens in Vietnam. Lancet 2009;374:1410.

4. Guilmoto CZ, Hoang X, Van TN. Recent increase in sex ratio at birth in Viet Nam. PLoS One 2009;4:e4624.

5. Hesketh T, Xing ZW. Abnormal sex ratios in human populations: causes and consequences. Proc Natl Acad Sci U S A 2006;103:13271-5.

6. Jha P, Kumar R, Vasa P, et al. Low female-to-male sex ratio of children born in India: national survey of 1.1 million households. Lancet 2006;367:211-8.

7. Sen A. Missing women. BM7 1992;304:587-8.

8. Sen A. Missing women — revisited. BM7 2003;327:1297-8.

9. Abrebaya J. Are there missing girls in the United States? Evidence from birth data. Am Econ 7 Appl Econ 2009;1:1-34.

10. Almond D, Edlund L. Son-biased sex ratios in the 2000 United States Census. Proc Natl Acad Sci US A 2008;105:5681-2.

11. Almond D, Edlund L, Milligan K. Son preference and the persistence of culture: evidence from South and East Asian immigrants to Canada. Popul Dev Rev 2013;39:75-95. 
12. Dubuc S, Coleman D. An increase in the sex ratio of births to India-born mothers in England and Wales: evidence of sex-selective abortion. Popul Dev Rev 2007;33:383-400.

13. Ray JG, Henry DA, Urquia ML. Sex ratios among Canadian liveborn infants of mothers from different countries. CMA7 2012;184:E492-6.

14. Tønnessen M, Aalandslid V, Skjerpen T. Changing trend? Sex ratios of children born to Indian immigrants in Norway revisited. BMC Pregnancy Childbirth 2013;13:170.

15. Chahnazarian A. Determinants of the sex ratio at birth: review of recent literature. Soc Biol 1988;35:214-35.

16. Jacobsen R, Moller H, Mouritsen A. Natural variation in the human sex ratio. Hum Reprod 1999;14:3120-5.

17. Markle GE. Sex ratio at birth: values, variance, and some determinants. Demography 1974;11:131-42.

18. Wilcox A. Fertility and pregnancy. An epidemiologic perspective. New York: Oxford University Press; 2010.

19. Parker JD, Madans JH. The correspondence between interracial births and multiple-race reporting. Am 7 Public Health 2002;92:1976-81.

20. Preventing gender-biased sex selection. An interagency statement $\mathrm{OHCHR}$, UNFPA, UNICEF, UN Women and WHO. Geneva: World Health Organization; 2011.

21. Urquia ML, Moineddin R, Jha $\mathrm{P}$, et al. Sex ratios at birth after induced abortion. CMA72016 Apr. 11 [Epub ahead of print].

22. Puri S, Adams V, Ivey S, et al. "There is such a thing as too many daughters, but not too many sons": a qualitative study of son preference and fetal sex selection among Indian immigrants in the United States. Soc Sci Med 2011; 72:1169-76.

23. Rogers JLDD. Does having boys or girls run in the family? Chance 2001; 14:8-13.

24. Sever A. Discarded daughters: the patrialchal grip, dowry deaths, sex ratio imbalances \& foeticide in India. Womens Health Urban Life 2008;7:56-75.
Affiliations: Centre for Research on Inner City Health (Urquia, Ray, Wanigaratne, O'Campo), Li Ka Shing Knowledge Institute, St. Michael's Hospital; Dalla Lana School of Public Health (Urquia, O'Campo), University of Toronto; Departments of Medicine and Obstetrics and Gynaecology (Ray), St. Michael's Hospital; Department of Family and Community Medicine (Moineddin), Faculty of Medicine, University of Toronto, Toronto, Ont.

Contributors: Marcelo Urquia conceived the study and acquired the data. Marcelo Urquia and Rahim Moineddin analyzed the data. Marcelo Urquia wrote the first draft of the paper. Marcelo Urquia, Joel Ray, Susitha Wanigaratne and Patricia O'Campo contributed to the study design and interpretation of the results. All authors made suggestions about the content, approved the final version to be published and agreed to act as guarantors of the work.

Funding: This research was supported by funds to the Canadian Research Data Centre Network from the Social Science and Humanities Research Council, the Canadian Foundation for Innovation and Statistics Canada. Although the research and analysis are based on data from Statistics Canada, the opinions expressed do not represent the views of Statistics Canada or the Canadian Research Data Centre Network. Marcelo Urquia holds a Canadian Institutes for Health Research (CIHR) New Investigator Award. Joel Ray has a CIHR Chair in Reproductive and Child Health Services and Policy Research. Susitha Wanigaratne is supported by a CIHR grant.

Supplemental information: For reviewer comments and the original submission of this manuscript, please see www.cmajopen.ca/content/4/2/ E116/suppl/DC1 